\section{Fludd's philosophy}

\section{P. M. Rattansi}

Robert Fludd and His Philosophicall Key. Introduction by Allen G. Debus. Pp.156. (Neale Watson: New York, 1979.) $\$ 40, £ 20$.

IN 1620 Francis Bacon published his Novum Organum, with a dedication to James I, urging him to support his enterprise, "that so at length, after the lapse of so many ages, philosophy and the sciences may no longer float in air, but rest on the solid foundation of experience of every kind ...". At about the same time, the physician Robert Fludd had completed a Philosophicall Key "to unlock and open the meanings of that Macrocosmicall and Microcosmicall Philosophy'. He, too, dedicated it to James I, hoping the King's patronage would shield him "from the Harpys talents and envious endeavours of this World"'.

Fludd agreed with Bacon that Aristotelian science was to be replaced by one based on "ocular demonstration" and dedicated to the relief of human misery. Like him, he praised atomism, but was more inclined to explain nature's operations in terms of a 'spirit' active in all things. But Fludd believed in a 'Christian' philosophy of nature, the principles of which would be drawn from the account of creation in the text of Genesis. Bacon condemned the "unwholesome mixture of things human and divine" since it gave rise to "not only a fantastic philosophy but also an heretical religion". Fludd associated the greatest secret in nature, the principle of life, with light and the breath of the Lord, while Bacon denounced such notions as "superstitious".

His major works had already appeared in Latin, and had involved Fludd in controversies with Kepler, Mersenne and Gassendi. The Key was written in English to silence critics at home. Fludd thought his "experimental demonstrations" would convince readers of the truth of his ideas. Relying on an analogy between the Sun in the Universe, the heart in the human body, gold in the metalline and wheat in the vegetable kingdoms, Fludd chose to concentrate on experiments on wheat. After all, had it not been compared to the Second Person of the Trinity, and was it not Christ's referring to bread as his body which had set the Christian world "in combustion"?

The planting of the seed in the ground and the generation of wheat had exemplified the pattern of death and resurrection to the Christian alchemist. Fludd pointed out that as the plant grew, the quintessence in it rose to the stalk and was concentrated in the wheat grain. By a sympathetic magnetism, the most spiritual part of the plant would then draw down more and more of the aerial spirit. This process could be emulated by the chemist, and Fludd believed he had succeeded in obtaining the universal spirit in the form of a "white christalline" substance.

Fludd's claims may seem extravagent to us, his reasoning contorted and his "ocular demonstrations" quite unconvincing. It is discomforting, therefore, to recognize in his work themes which recent historical research has unearthed in the alchemical studies which occupied a great deal of Isaac Newton's most creative period: the true interpretation of the alchemical foundation text, the 'Emerald Tablet'; the 'magnet' to draw down the aerial quintessence; and the involvement of light in generation in the three kingdoms of

\section{Recombination in phage and fungi}

\section{H.L.K. Whitehouse}

Genetic Recombination: Thinking about it in Phage and Fungi. By F. W. Stahl. Pp.333. (Freeman: San Francisco and Oxford, 1979.) $£ 12.90$.

THE publication of a book on genetic recombination by one of the leading workers in the field is an important event for geneticists. Recombination was discovered in the early years of this century and became a central issue in genetics with the realization that exchange of segments between homologous chromosomes was involved, in addition to the random orientation of the paternal and maternal members of each chromosome pair on the spindle at the first meiotic division. Recombination took on a new dimension about 30 years ago with the discovery of its occurrence in prokaryotes, and with the recognition that both in prokaryotes and eukaryotes understanding the process of exchange was likely to require detailed knowledge of the biochemistry of DNA. Since that time it has been essential, if a general view of the subject was to be obtained, that results derived from prokaryotes and eukaryotes should be integrated. To achieve such integration is difficult, as the life-cycles, and therefore the experimental techniques and kind of information obtained, are so different: the prokaryote- and the eukaryote-worker speak such different languages that they may barely understand one another. It is greatly to Stahl's credit that he has attempted in this book to bring about a synthesis of results from bacteriophages and from fungi, as these are the organisms that have contributed most from each kingdom. The phages discussed are lambda and T4 of Escherichia coli. nature. He represents a style of thought which cannot be neglected if we are fully to comprehend those whom we recognize as the pioneers of modern science.

The Key has been published for the first time from the manuscript at Trinity College, Cambridge, with an Introduction by Allen G. Debus. The text itself occupies 93 pages and has been supplemented with an extensive account of the life and work of Fludd. The work, written in a rhapsodic style which occasionally breaks into verse, makes Fludd's ideas a little more accessible to the modern reader.

P. M. Rattansi is Professor in the Department of History and Philosophy of Science, University College, University of London, UK.

The first two chapters give the basic information about the exchange process obtained from progeny chosen on a random basis, in fungi and phages, respectively; and the next two chapters give the fuller picture when both products of an exchange are recovered - that is, tetrad analysis and single burst analysis. The implications of the duplex structure of DNA are introduced in Chapter 5. Then follows an important chapter on the surprising results that have been obtained, both in phages and fungi, from investigations with very closely linked mutants. Together with an appendix giving the algebraic basis of the concepts introduced, this chapter constitutes one quarter of the entire book. The following two are concerned with conversion and its association with crossing-over; and, after a consideration of recombination chemistry, the book concludes with lengthy discussions of current hypotheses. There is no account of transposons or phage Mu.

The lay-out of the chapters, although logical, does not necessarily make the subject matter easy to comprehend, and certainly leads to considerable repetition. Thus, having learnt in the first chapter that crossing-over takes place between homologous chromosomes, one has in a later chapter to replace this with the notion that the exchanges occur between daughter chromatids rather than whole chromosomes. Again, in discussing aberrant asci, one of the five basic kinds is treated in a different chapter from the others, because it does not have unequal numbers of the two parental genotypes and therefore does not qualify for consideration in a chapter on conversion. Yet all the types of aberrant segregation are associated with crossing. over and it is arguable that the simplest approach is to treat them all together.

Some of the difficulty for students in understanding what is known about genetic recombination derives from complexities inseparable from the organisms investigated. Thus, in lambda not only are there two recombination 
systems specific to it, but the host recombination pathways also act on the phage. Furthermore, the method by which lambda packages its DNA in the head of the virus probably leads to a bias in the recombination events shown by the progeny. With T4 the complexity of the experimental results arises from the extraordinary genetic system that prevails in this phage, which has linear genomes that are circularly permuted with respect to one another. Although a concise account is given of the relevant results, it would be an advantage to students if they already had some knowledge of recombination studies with $E$. coli and these phages.

The book is addressed to graduate students and final-year undergraduates, but I fear that many will find it difficult reading. The problems at the end of each chapter will no doubt help towards a better understanding, though some of these will certainly present a severe challenge for students. Fortunately, the solutions are given later in the book. The clarity of thought that the book constantly demands is helped by a profusion of unnumbered small diagrams which form an integral part of the text. In some of the diagrams the differences in line thickness that indicate the parentage are easily overlooked, and there are no legends to draw one's attention to them. The author's entertaining, often colloquial, style helps to enliven the book.

Errors are few, but Figures 8-1 and 8-2 have been transposed and an incorrect reference is given in this chapter for data on
Sordaria asci with 5:3 ratios for spore colour. In the previous chapter Rossignol and Haedens' work is discussed without reference to them. There is a useful glossary but Stahl's new term, 'splatch', is not included though freely used in the text. It is surprising in a book on genetic recombination to find no reference to the important contributions to the subject by Benbow et al., Ephrussi-Taylor et al., Spatz and Trautner or Tiraby et al., even though their work relates to organisms other than those with which the book is primarily concerned.

My chief criticism of Stahl's book is that it does not give a balanced view of the current state of knowledge of recombination in eukaryotes. Hypotheses involving fixed pairing segments, such as his so-called "sex-circle" model, are discussed without drawing adequate attention to the conflict they present with a considerable body of data. He lists eleven features of the recombination data for Saccharomyces cerevisiae and implies that these results are so different from those found with other fungi as to demand a quite different explanation. But most of the results with yeast have also been found in other fungi; and to me the similarities are much more impressive than the differences. He supports the idea of break-andcopy by reference to work on phage $\mathrm{fl}$ without acknowledging that the authors subsequently abandoned this hypothesis for a more conventional one depending on heteroduplex DNA. And why suppose that in fungi two crossovers (reciprocal exchanges) may occur in very close proximity in the same two chromatids when there is no evidence for this? Stahl repeatedly raises the subject of interference between crossovers, even to the final sentence of the text, where he says "... we would all feel better if a good molecular explanation for the facts of interference were neatly wedded to some of those models", referring to those he has been discussing. But he seems to overlook the very great distances, in molecular terms, over which interference often acts, and the lack of it across the centromere. It seems likely that interference is a phenomenon superimposed on the basic crossover mechanism rather than a primary feature of it. When discussing Holliday's recombination model in Chapter 8 , Stahl argues that interference should lead to an excess of recombinant over parental flanking marker genotypes in association with conversion, but Holliday himself (Phil. Trans. R. Soc. B277, 367; 1977) draws the opposite conclusion.

Despite these criticisms, Dr Stahl is to be congratulated for producing such a challenging and thought-provoking, if controversial, work. It should draw attention to the many unsolved problems in this field and provide a stimulus for further research.

H.L.K. Whitehouse is Reader in Genetic Recombination in the Department of Botany, University of Cambridge, UK.

\section{Illustrated black holes}

\section{R.L. Znajek}

Black Holes. By W. Sullivan. Pp.303. (Anchor Press/Doubleday: Garden City, New York, 1979.) \$17.95.

SullivaN's Black Holes begins with a bang. Literally. The first chapter is about the Tunguska event - the great Siberian explosion of 1908 . This is tenuously linked to the title by a theory that the explosion was caused by a small black hole falling through the atmosphere (Jackson and Ryan, Nature 245, 88-89; 1973). Like all good theories it made a prediction: the hole passed through the Earth and emerged over the North Atlantic Ocean, causing a similar explosion as it left. This should have caused atmospheric vibrations comparable to those detected from the original event. It turned out that no such vibrations were detected from the North Atlantic (Beasley and Tinsley, Nature 250, 555-556; 1974), and so the theory now seems untenable. There is of course no shortage of other ideas, ranging from the exotic (an exploding nuclear-powered spacecraft) to the quite plausible (a small comet or meteorite). Sullivan tells us about all of them, and this gets him into digressions about anti-matter and carbon-14 dating. We are treated to maps, eyewitness reports and even photographs of a man who was blown off his porch by the blast. It is mostly quite interesting. Like the rest of the book, it has little to do with black holes. But the title presumably sells.

Black Holes is in fact an account of some of the more dramatic goings-on in modern astronomy. It deals with white dwarfs, pulsars, X-ray sources, quasars and cosmology, as well as with things that might have exploded over central Siberia. Sullivan, being Science Editor of the New York Times, writes in an appropriately journalistic 'who-did-what' manner. He emphasizes observations and is short on theory. The trouble is that black holes are inherently theoretical objects. They cannot, by definition, be seen or photographed. Events happening near a black hole can be observed, and the hole's presence deduced theoretically. A book about black holes should certainly explain why many astronomers think they exist, and this one does. It should also make a serious attempt to explain what they are, and this means more than just stating that gravity becomes so strong that not even light can escape.

I am not asking for a layman's guide to tensor calculus and the Einstein equations. I am suggesting that one can give a precise but non-mathematical account of relevant aspects of special and general relativity, such as light cones and frames of reference. By showing how light cones are tilted at the surface of a black hole, one can demonstrate why the surface is an 'event horizon' and why leaving it is precisely equivalent to travelling faster than light. (A spaceship that can travel faster than light can get out of a black hole. Scientists depicted in the recent film The Black Hole seem surprisingly ignorant of this fact.) Laymen may not understand mathematics, but most of them can read maps, and so any popular account of black holes should include plenty of space-time diagrams, which are just maps showing the location of events in space and time. The best example of what I have in mind is Kaufmann's book The Cosmic Frontiers of General Relativity (Little, Brown: Boston, 1977), which might almost be accused of being overillustrated. Sullivan's book is crammed with photographs of astronomers, telescopes, rockets and galaxies, but I cannot 